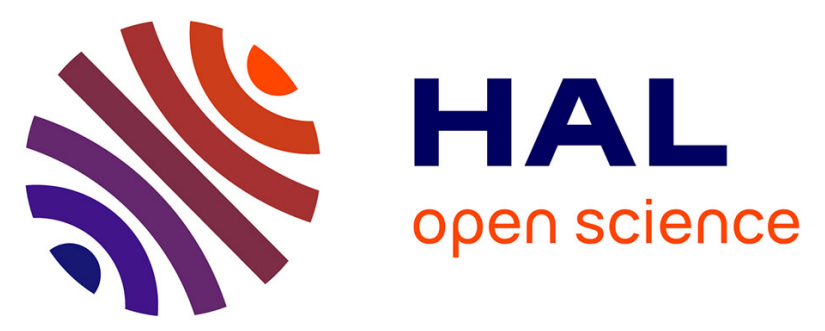

\title{
On the choice of the dielectric characterization method for foam composite absorber material
}

Laura Pometcu, Chloé Mejean, Ratiba Benzerga, Ala Sharaiha, Philippe Pouliguen, Claire Le Paven

\section{- To cite this version:}

Laura Pometcu, Chloé Mejean, Ratiba Benzerga, Ala Sharaiha, Philippe Pouliguen, et al.. On the choice of the dielectric characterization method for foam composite absorber material. Materials Research Bulletin, 2017, 96 (2), pp.107 - 114. 10.1016/j.materresbull.2017.04.055 . hal-01585678

\section{HAL Id: hal-01585678}

\section{https://hal-univ-rennes1.archives-ouvertes.fr/hal-01585678}

Submitted on 18 Oct 2017

HAL is a multi-disciplinary open access archive for the deposit and dissemination of scientific research documents, whether they are published or not. The documents may come from teaching and research institutions in France or abroad, or from public or private research centers.
L'archive ouverte pluridisciplinaire HAL, est destinée au dépôt et à la diffusion de documents scientifiques de niveau recherche, publiés ou non, émanant des établissements d'enseignement et de recherche français ou étrangers, des laboratoires publics ou privés. 


\section{Accepted Manuscript}

Title: On the choice of the dielectric characterization method for foam composite absorber material

Authors: Laura Pometcu, Chloé Méjean, Ratiba Benzerga, Ala Sharaiha, Philippe Pouliguen, Claire Le Paven

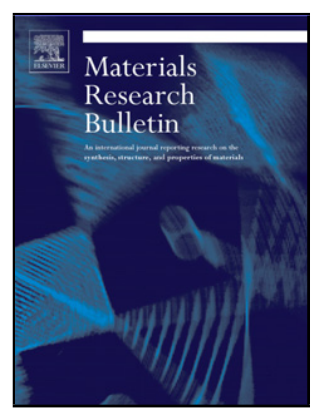

PII:

S0025-5408(16)30363-4

DOI: http://dx.doi.org/doi:10.1016/j.materresbull.2017.04.055

Reference: MRB 9353

To appear in: $M R B$

Received date: 21-7-2016

Revised date: 19-4-2017

Accepted date: 27-4-2017

Please cite this article as: Laura Pometcu, Chloé Méjean, Ratiba Benzerga, Ala Sharaiha, Philippe Pouliguen, Claire Le Paven, On the choice of the dielectric characterization method for foam composite absorber material, Materials Research Bulletinhttp://dx.doi.org/10.1016/j.materresbull.2017.04.055

This is a PDF file of an unedited manuscript that has been accepted for publication. As a service to our customers we are providing this early version of the manuscript. The manuscript will undergo copyediting, typesetting, and review of the resulting proof before it is published in its final form. Please note that during the production process errors may be discovered which could affect the content, and all legal disclaimers that apply to the journal pertain. 


\section{On the choice of the dielectric characterization method for foam composite absorber material}

Laura Pometcu ${ }^{l}$, Chloé Méjean ${ }^{1}$, Ratiba Benzerga ${ }^{1, *}$, Ala Sharaiha ${ }^{1}$, Philippe Pouliguen $^{2}$, Claire Le Paven ${ }^{1}$

\footnotetext{
${ }^{1}$ Institut d'Electronique et de Télécommunications de Rennes, Université de Rennes 1, 22004 Saint-Brieuc, France

${ }^{2}$ Research and scientific innovation department of DGA, 92221 Bagneux, France
}

* Corresponding author: R. Benzerga, ratiba.benzerga@univ-rennes1.fr 
Graphical abstract

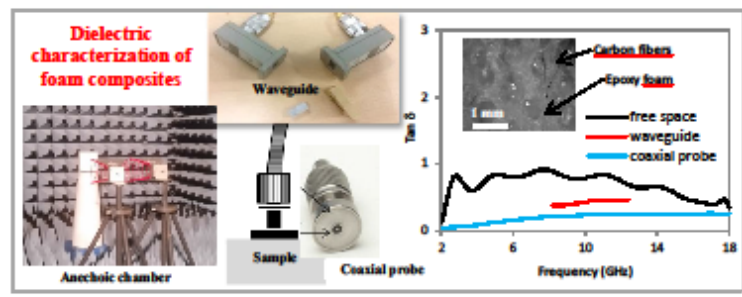

Highlights

- Dielectric characterization of carbon fibers loaded epoxy composites has been done.

- Free space, waveguide and coaxial probe technics are used for the characterization.

- Free space is the adapted technic for the heterogeneous composite characterization.

- Simulation and measurement of the reflectivity of absorber porotype have been done. 
Abstract - This paper presents the characterization by three different techniques of a new lossy material made of carbon fibers loaded epoxy foam that can be used as an absorber in anechoic-chambers. The composite was characterized using free space, waveguide and coaxial probe techniques. Dielectric characteristics obtained from the three techniques are different and this is explained by the required dimensions of measured samples, not always representative of the porous form of the composites loaded with long fibers. Our study points out that the free space technique is the most appropriate to measure such composite samples with porosities and load having millimeter dimensions. Dielectric probe and waveguide are not suitable due to a small volume of measure which is not representative of the entire composite. The achieved prototype confirmed this result with a measured reflection coefficient very close to the simulation achieved with the dielectric characteristics obtained by the free space technique.

Keywords - Dielectric properties; composites; organic compounds; Carbon fibers; Epoxy foams.

\section{INTRODUCTION}

Microwave absorber materials are used extensively in anechoic chambers (AC) to emulate free-space conditions and to suppress unintended radiations of the in-situ electronic equipment [1]. The choice of an absorber material for an AC use is based on its absorption performance, as well as its density and also its cost since a significant amount of materials is necessary to cover the entire surface of the AC. Different associations «polymer» + «carbon filler» are currently studied as absorbers, for example, resins loaded with carbon particles [2], resins loaded with carbon nanotubes [3], polymer foams loaded with carbon nanotubes [4] or resins loaded with carbon fibers [5]. The most used absorber material in AC is the polyurethane (PU) foam loaded with fine carbon particles [6]. Here, we propose to study the dielectric characteristics of an original composite which associates long carbon fibers with epoxy foam. 
Several studies have been carried out on carbon fibers mixed with epoxy resin $[7,8]$, but, up to now, the density of the resin has limited its use as an absorber in AC. Then, the advantage of the epoxy foam compared to bulk resin is obviously the low density of the produced material, appropriate for its application in AC. In addition, another advantage of the epoxy foam, compared to the PU foam, lies in its high mechanical rigidity [9] which allows a machining under complex form to optimize the absorption performances [10, 11].

The characterization of absorbing materials usually shows a decrease of the electromagnetic signal in certain frequency ranges depending on the composition as well as the overall geometry of the measured material. Moreover, available dielectric characterization techniques often present constraints, such as the size of samples needed for the characterization. For example, free space techniques require materials with large dimensions, contrary to coplanar techniques which need very thin samples. On the other hand, the waveguide technique requires samples with precise dimensions that will decrease as the measurement frequency increases. Another constraint is the frequency range of the measurement, sometimes limited, such as in the case of a resonant cavity for which only one frequency is explored, or in the case of a waveguide which works in a very short frequency range. The broadband techniques often need very large samples (several tens of $\mathrm{cm}^{3}$ ) that cannot be obtained for all type of materials.

The purpose of the present article is to characterize by three different techniques an absorbing composite made of the association of epoxy foam and carbon fibers. The objective is to find the most suitable technique for this type of "heterogeneous" (i.e. composite) material. Free space, X-band waveguide and dielectric probe measurement methods were used. The article is composed as follows: the first part briefly explains the elaboration of the composite samples, the second part details each of the three dielectric characterization techniques, the third part presents and discusses the results of the different measurements and the final part introduces the achievement and the measurement of a prototype, having a commercial 
geometry, in order to validate the dielectric properties obtained by one or more of the characterization methods.

\section{ELABORATION OF CARBON FIBERS LOADED EPOXY FOAMS}

The carbon fibers used in this study are $3 \mathrm{~mm}$ length and $7 \mu \mathrm{m}$ diameter (provided by Apply Carbon SA). For the composite elaboration, we have used epoxy foam made from commercial epoxy resin and hardener from Sicomin [9]. The elaboration process of our material is described as follows. The chosen weight percentage of carbon fibers (here, between 0 wt. \% and $1 \mathrm{wt} . \%$ ) is added to the epoxy resin and mixed for a few minutes before the hardener agent is added. The latter induces the foaming process and the polymerization reaction of the resin (6 hours step). At last, thermal treatment is achieved during 6 hours at $60^{\circ} \mathrm{C}$ in order to complete the polymerization reaction and to fix the mechanical properties of the foam composite. Finally, the samples are cut to the desired geometry required for the measurements. Here, three techniques, with samples having different sizes, have been used to determine the dielectric properties of the composites.

\section{BASIC CONCEPTS OF THE CHARACTERIZATION METHODS}

\subsection{FREE SPACE TECHNIQUE}

The free space method [12] is a nondestructive technique that can be used in a large frequency band. A schematic of the microwave measurement setup is given in Fig. 1. Two reflection coefficients $\left(S_{11}\right)$ of the material are measured, respectively, with and without a metallic ground plane behind the sample. The complex permittivity of the characterized 
material is extracted from the two measured $\mathrm{S}_{11}$ coefficients using the method of Fenner and al [13].

For this technique, the dimensions of samples are $15 \times 15 \times 6.5 \mathrm{~cm}^{3}$. Two ultrawideband (UWB) antennas (ETS-Lindgren's Model 3115 Double-ridged Waveguide Horn) of size $24.4 \mathrm{~cm}$ x $15.9 \mathrm{~cm}$ x $27.9 \mathrm{~cm}$ (length $\mathrm{x}$ width $\mathrm{x}$ depth) are used. The antennas are placed in front of the characterized sample (in order to have a normal incidence of the electromagnetic wave) and are coupled to a Vector Network Analyzer. The distance between sample and antennas is $113 \mathrm{~cm}$. The latter is calculated considering far field (Fraunhofer) conditions (Eq.13) [14] at the lowest measured frequency.

$$
\begin{gathered}
R=\frac{2 * D^{2}}{\lambda} \\
R \gg D \\
R \gg \lambda
\end{gathered}
$$

where $R$ is the distance between sample and antennas, $D$ is the antenna aperture diameter and $\lambda$ the higher measured wavelength.

\subsection{X-BAND WAVEGUIDE}

The second technique used for the characterization of the epoxy composite material is a waveguide. This technique is very popular and widely used [15 - 17] but it is narrowband and it requires a sample with a specific size depending on the frequency band of measurement (large samples for low frequencies and, inversely, very small samples for high frequencies). Moreover, samples have to be cut to very precise dimensions in order to perfectly enter the slot and so to prevent the formation of any air voids between the sample and the walls of the waveguide. In this study, we have performed measurements with an X-band waveguide working between $8.2 \mathrm{GHz}$ and $12.4 \mathrm{GHz}$ (Fig. 2.). For this frequency range, the samples are smaller than those used for free space technique and must have a (theoretical) size of $22.86 \mathrm{x}$ $10.16 \times 9.7 \mathrm{~mm}^{3}$. 
The method used to extract the complex permittivity of the material is the Nicolson-RossWeir technique $[18,19]$ which uses the measured reflection $\left(S_{11}\right)$ and transmission $\left(S_{21}\right)$ coefficients.

\subsection{OPEN ENDED COAXIAL PROBE}

The third technique uses a dielectric coaxial probe $85070 \mathrm{E}$ from Keysight (Fig. 3.a). It is connected to an 8510C Keysight vector network analyzer. For this characterization, the sample surface state is very important. Indeed, the surface in contact with the dielectric probe should be as flat as possible to avoid any air gap which would induce an underestimation of the complex permittivity. Samples have a surface of at least $2 \times 2 \mathrm{~cm}^{2}$, greater than the surface of the probe (Fig. 3.b). With the dielectric coaxial probe, the complex permittivity of the characterized sample $\left(\varepsilon=\varepsilon^{\prime}-\mathrm{j} \varepsilon^{\prime \prime}\right)$ is directly obtained; the dielectric loss tan $\delta$ is calculated as the ratio of the imaginary part $\left(\varepsilon^{\prime \prime}\right)$ upon the real part $\left(\varepsilon^{\prime}\right)$ of the complex permittivity.

To minimize the measurement uncertainty, 8 measurements are performed for each sample, and the mean value is calculated. Standard deviations of $5 \%$ and $20 \%$ have been estimated from the 8 measurements, for permittivity and dielectric loss, respectively.

\section{DiELECTRIC CHARACTERIZATION RESUlTS}

\subsection{FREE SPACE CHARACTERIZATION}

Photos of the composite samples used for the free space measurement are shown in Supplementary data 1. Different carbon fiber load percentages (between $0 \mathrm{wt} \%$ and $1 \mathrm{wt} \%$ in weight) were used. It should be noted that the grey coloration of samples is becoming darker as the percentage of carbon fibers increases. 
Remind that, for this technique, two measurements of the reflection coefficient have to be done to extract the complex permittivity: the sample alone and the sample backed by a metallic plate. At least, 4 measurements have been done on each sample in order to check the reproducibility of the measurements. All the reflection coefficients are very close.

Fig. 4.a and 4.b present the evolution of the reflection parameter $\left(\mathrm{S}_{11}\right)$ as function of frequency for the samples with different carbon fibers load, respectively, without and with the metallic plate. Fig. 4.c and 4.d show the extracted permittivity and dielectric loss, respectively.

For the measurement without metallic plate (Fig. 4.a) and for the unloaded sample, $\mathrm{S}_{11}$ values are below - $20 \mathrm{~dB}$ on the entire studied frequency range. This signifies a low reflection for this sample at the interface air/sample. As the load rate of carbon fibers in the composite increases, the reflection coefficient increases; for example, the value of $S_{11}$ parameter is around - $8 \mathrm{~dB}$ at $10 \mathrm{GHz}$ for the $1 \mathrm{wt} \% \%$ carbon fibers loaded composite. Concurrently, the permittivity of the material increases (Fig. 4.c); for example, the permittivity of the material loaded with 1 wt. $\%$ is 2.03 at $10 \mathrm{GHz}$ (unloaded: $\varepsilon^{\prime}=1.20$ ). In fact, the increase of the reflection coefficient without metallic plate is due to an increasing mismatch of the relative impedances at the interface air/material as the permittivity of the composite increases under the effect of the carbon load. If the impedance characteristic of the composite is lower than 377 ohms (relative impedance of free space), the reflection at the interface air/material is high and the material is no longer a good absorber.

For the measurement with metallic plate (Fig. 4.b), the reflection is close to $0 \mathrm{~dB}$ for the unloaded sample (meaning that the reflection is nearly complete at the interface sample/metallic plate). The reflection decreases as the carbon load increases; for example, the reflection coefficient of the 1 wt. \% carbon fibers loaded composite (backed with metallic plate) is around $-8 \mathrm{~dB}$, at $10 \mathrm{GHz}$. That means that loaded composites absorb waves whereas the unloaded does not. Nevertheless, a compromise is needed since the reflection at the interface air/material also increases with carbon load. Concerning the dielectric loss, Fig. 4.d 
shows that the composite materials have high $\tan \delta$, which increases with the increase of the load rate. A dielectric loss ( $\tan \delta$ ) of 0.001 and 1.39 are obtained for, respectively, unloaded and 1 wt.\% loaded composites at $10 \mathrm{GHz}$.

Retro-simulations, using CST Microwave Studio software, have been done to verify the extracted values of the permittivity. Results are given in Supplementary data 2. They show a quasi-perfect correlation between simulation and measurement for all samples (Fig. 4.a and Fig. 4.b). This definitively validates the method of extraction of the complex permittivity.

\subsection{WAVEGUIDE CHARACTERIZATION}

Photos of the composite samples used for the X-band waveguide measurements are shown in Supplementary data 3. Carbon fiber load percentages between 0 wt.\% and 1 wt.\% were used to achieve these samples. For each composition, two samples have been achieved; each of them has been characterized 4 times. It is worth nothing that these different measurements showed some variations. Indeed, the obtained transmission coefficients $\left(\mathrm{S}_{21}\right)$ are very close to each other while a large variation is sometimes observed on the reflection coefficients $\left(\mathrm{S}_{11}\right)$. In this paper, the more reproducible values are presented.

Fig. 5.a and Fig. 5.b present, respectively, the reflection $\left(\mathrm{S}_{11}\right)$ and transmission $\left(\mathrm{S}_{21}\right)$ coefficients obtained from X-band waveguide measurements for the different carbon loadings. The extracted complex permittivity allows determining the real part of permittivity and dielectric loss, presented in Fig. 5.c and Fig. 5.d. They show that the dielectric properties of the unloaded ( 0 wt. $\%)$ and low-loaded $(0.25$ wt. $\%$ carbon fibers) composite foams are similar. As carbon load increases further, tan $\delta$ increases and is maximum for the $1 \mathrm{wt} . \%$ carbon load composite $(\tan \delta=1.06$ at $10 \mathrm{GHz})$. At the same time, permittivity values are more or less similar. 
These results are very different from the ones obtained in free space. This is probably due to the dimensions of the samples used for the waveguide which are very small compared to the ones used for the free space measurements. In fact, the materials studied here have heterogeneous structure and composition by their nature of composites and foams. The porous nature of the epoxy foam (with millimetric porosities) and the addition of carbon fibers $3 \mathrm{~mm}$ length, make the composite heterogeneous at a millimetric scale, which is the scale of the waveguide measurement in the X-band. As the carbon fibers load increases, this heterogeneity increases as shown by the different sizes of porosities in Fig. 6. For this reason, it appears very difficult to characterize this type of material using the waveguide technique because the small characterized sample is not representative of the entire composite material.

\subsection{OPEN ENDED COAXIAL PROBE}

Fig. 7 presents the permittivity and dielectric loss obtained by the open ended coaxial probe technique for the different foam composites. $\varepsilon^{\prime}$ and $\tan \delta$ increase as the carbon load increases, as previously observed with the two other characterization techniques. However, the dielectric properties measured here appear to be lower than those measured previously by free space (Fig. 4.c and Fig. 4.d) and by waveguide (Fig. 5.c and Fig. 5.d). Permittivity, at $10 \mathrm{GHz}$, of the 1 wt.\% loaded foam is $\varepsilon^{\prime}=1.76$, smaller than those obtained by free space measurement $\left(\varepsilon^{\prime}=\right.$ 2.03) and waveguide measurement $\left(\varepsilon^{\prime}=2.99\right)$. Losses are also significantly lower than previously, for example, the measured value here is $\tan \delta=0.24$ at $10 \mathrm{GHz}$ for the $1 \mathrm{wt} . \%$ carbon load composite, while it was 1.39 and 1.06, respectively, for the free space and waveguide measurements. These discrepancies can be explained by the existence of an air gap (due to imperfect planar surface of sample) as well as millimetric dimension of porosities, both under-estimating $\varepsilon^{\prime}$ and $\tan \delta$. 


\subsection{DISCUSSION}

Three techniques have been used to characterize absorbing composites. They present different dielectric characteristic in terms of permittivity and dielectric loss, as summarized in Supplementary data 4 , for the $0.5 \mathrm{wt} . \%$ carbon fibers loaded composite.

Losses determined in free space are significantly higher than those measured by waveguide and coaxial probe. This can be explained by the fact that only a small volume is analyzed by the latter two techniques as emphasized by Fig. 8.b.c, too low to be representative of the entire foam sample with porosities and fibers in the millimetric scale (Fig. 8.d). In addition, as the surface of the foam is irregular, this inexorably leads to a certain roughness of the samples, which is known to greatly influence the characterization by the waveguide and coaxial probe methods [20, 21]. These two techniques are also very sensitive to the presence of any air gaps as pointed out by $[20,22,23]$. All these features will finally lead to an under-estimation of the measured dielectric properties $[20,22,24]$. In the case of the coaxial probe, this is accentuated by the fact that the measurement is punctual, and therefore much localized. In fact, this technique is more suitable for liquid samples [24, 25], but it is often used for the characterization of solid samples for its simplicity of use [26, 27, 28].

To summarize, the free space technique seems to be the most likely to access the intrinsic characteristics of loaded composite foams than the coaxial probe or waveguide techniques. Moreover, in our case, the frequency range of measurement of the waveguide technique is very narrow, compared to the frequency range of targeted application of our absorbers. The achievement of a prototype absorber (i.e., at the actual scale) and its measurement in anechoic chamber will come to confirm it. 


\section{ELABORATION AND CHARACTERIZATION OF A CARBON FIBERS LOADED} EPOXY FOAM PROTOTYPE

In order to validate the dielectric properties obtained with the different techniques, the simulation of the reflection coefficient of a pyramidal absorber was conducted using the dielectric characteristics obtained from each of the three techniques. These simulations, achieved with the CST Microwave Studio software, were compared to the measurement of a prototype in an anechoic chamber.

The chosen absorber geometry for a prototype is the one of the APM12 commercial absorber from SIEPEL [6]. It consists of a combination of square-based pyramids, of $9 \mathrm{~cm}$ high and $3.8 \times 3.8 \mathrm{~cm}^{2}$ base deposited on a $2.5 \mathrm{~cm}$ thick base (Fig. 9.a). The photo of the achieved prototype, which contains 64 pyramids, is presented in Fig. 9.b. For this prototype, the 0.5 wt.\% loaded foam was chosen because it presents the best compromise to access a high absorption and prevent from too much reflection: high losses and a low permittivity, as well as a good homogeneity. Previous work [29] has emphasized the high absorption performance of this composition.

Fig. 10 presents the simulations of the reflection coefficient $\left(S_{11}\right)$ achieved with the dielectric characteristics obtained from the three techniques for the $0.5 \mathrm{wt} . \%$ carbon loaded foam composite. The simulation from coaxial probe predicts a low reflection $\left(\mathrm{S}_{11}<-40 \mathrm{~dB}\right)$ for frequencies above $9 \mathrm{GHz}$, whereas a rapid increase of the reflectivity is observed below. For example, the reflection coefficient reaches $-10 \mathrm{~dB}$ at $5.5 \mathrm{GHz}$. Here, it must be remembered that the material must have a maximum threshold of reflectivity near $-10 \mathrm{~dB}$ to be considered as a good absorber [30]. The simulation obtained with the waveguide shows a reflection coefficient lower than $-45 \mathrm{~dB}$ between 8.2 and $12.4 \mathrm{GHz}$. The simulation made with the free space shows a reflection coefficient less than $-40 \mathrm{~dB}$ from 3.5 to $18 \mathrm{GHz}$; below, it increases but remains inferior to $-10 \mathrm{~dB}$. Fig. 10 also presents the measured reflection coefficient of the 
prototype. It shows a low reflection coefficient, lower than $-35 \mathrm{~dB}$, in the frequency range between 4 and $18 \mathrm{GHz}$. The reflectivity increases for lowest frequencies but it is still below the limited value of $-10 \mathrm{~dB}$.

The crucial point is that the simulation results obtained with the dielectric characteristics extracted from the free space measurements are very close to the measurement of the prototype, especially for low frequencies. This confirms our deductions on the relevance of the measurement of heterogeneous materials, such as porous or composite materials, by using a free space technique. It is adapted because it needs a large sample, so representative of the heterogeneous structure of loaded foam composite. Waveguide and coaxial probe techniques are less appropriate, especially at low frequencies for the coaxial technique. Nevertheless, due to its high sample size, the free space technique may not be suitable for any material, especially in routine tests.

\section{CONCLUSION}

This paper presents the dielectric characterization by three techniques of a new material for electromagnetic absorption in anechoic chambers. The composite, made of carbon fiber loaded epoxy foam, presents a heterogeneous composition and structure due to the presence of porosities and long fibers. It was characterized by free space, waveguide and coaxial probe techniques in order to extract its dielectric properties: permittivity and dielectric loss. Measurements show very different dielectric characteristics and led us to conclude that free space is the more adapted technique for the characterization of a heterogeneous structure such as foam composites. A 0.5 wt. $\%$ carbon fiber loaded material, which presents the best compromise of low permittivity, high loss and best homogeneity, was used to achieve an absorber prototype. The simulation of its reflection coefficient performed with the dielectric characteristics extracted with the free space technique is very close to the measured one. This 
result confirms that the free space technique is the adapted technique for heterogeneous composite characterization, especially for low frequencies $(<5 \mathrm{GHz})$.

\section{ACKNOWLEDGMENT}

The authors would like to thank the Direction Générale de l'Armement (DGA), France for their financial support. 


\section{REFERENCES}

[1] E. A. Drake, V. Rajamani, C. F. Bunting, J. C. West, B. Archambeault, and S. Connor, Extension and verification of absorbing material effectiveness on reducing electromagnetic emissions, IEEE Electromagnetic Compatibility and Signal Integrity (2015) 226-230, DOI: 10.1109/EMCSI.2015.7107690.

[2] W. S. Chin and D. G. Lee, Development of the composite RAS (radar absorbing structure) for the X-band frequency range, Composite Structures, vol. 77, no. 4 (2007) 457-465.

[3] A. Saib, L. Bednarz, R. Daussin, C. Bailly, Xudong Lou, J.-M. Thomassin, C. Pagnoulle, C. Detrembleur, R. Jerome, and I. Huynen, Carbon nanotube composites for broadband microwave absorbing materials, IEEE Transactions on Microwave Theory and Techniques, vol. 54, no. 6 (2006) 2745-2754.

[4] Y. Yang, M. C. Gupta, K. L. Dudley, and R. W. Lawrence, Novel Carbon Nanotube-Polystyrene Foam Composites for Electromagnetic Interference Shielding, Nano Letters, vol. 5, no. 11 (2005) 2131-2134.

[5] Z. Chu, H. Cheng, W. Xie, and L. Sun, Effects of diameter and hollow structure on the microwave absorption properties of short carbon fibers, Ceramics International, vol. 38, no. 6 (2012) 4867-4873.

[6] Siepel, Microwave pyramidal absorber APM. 2015.

[7] N. Zhao, T. Zou, C. Shi, J. Li, and W. Guo, Microwave absorbing properties of activated carbon-fiber felt screens (vertical-arranged carbon fibers)/epoxy resin composites, Materials Science and Engineering: B, vol. 127, no. 2-3 (2006) 207-211.

[8] M. Paligová, J. Vilčákova, P. Sáha, V. Křesálek, J. Stejskal, and O. Quadrat, Electromagnetic shielding of epoxy resin composites containing carbon fibers coated with polyaniline base, Physica A: Statistical Mechanics and its Applications, vol. 335, no. 3-4 (2004) 421-429.

[9] Sicomin, PB 170, PB 250, PB 400, PB 600 Cellular Epoxy Foam Production System. 2014. 
[10] L. Pometcu, A. Sharaiha, R. Benzerga, and P. Pouliguen, 'Straight wedge absorber geometry optimization for normal and oblique incidence', IEEE procceding of Loughborough Antennas and Propagation Conference (2014), 633-636. DOI: 10.1109/LAPC.2014.6996472.

[11] B. T. Dewitt and W. D. Burnside, 'Electromagnetic scattering by pyramidal and wedge absorber', IEEE Transactions on Antennas and Propagation, vol. 36, no. 7 (1988) 971-984.

[12] A. Brancaccio, G. D' Alterio, E. De Stefano, L. Di Guida, M. Feo, S. Luce, A Free-space Method for Microwave Characterization of Materials in Aerospace Application, Metrology for Aerospace (MetroAeroSpace), (2014) 423-427.

[13] R. A. Fenner, E. J. Rothwell, L. L. Frasch, A Comprehensive Analysis of Free-space and Guided-wave Techniques for Extracting the Permittivity and Permeability of Materials Using Reflection-only Measurements, Radio Science vol. 47 (2012) 1-13.

[14] R. L. Yadava, Antenna and wave propagation. 2011.

[15] A. Bogle, M. Havrilla, D. Nyquist, L. Kempel, and E. Rothwell, Electromagnetic material characterization using a partially-filled rectangular waveguide, Journal of Electromagnetic Waves and Applications, vol. 19, no. 10 (2005) 1291-1306.

[16] J. Baker-Jarvis, E. Vanzura, and W. Kissick, Improved technique for determining complex permittivity with the transmission/reflection method, IEEE Transactions on Microwave Theory and Techniques, vol. 38, no. 8 (1990) 1096-1103.

[17] J. Krupka, Frequency domain complex permittivity measurements at microwave frequencies, Measurement Science Technology, vol. 17 (2006) R55-R77.

[18] A. M. Nicolson, G. F. Ross, Measurement of the Intrisic Properties of Materials by Timedomain Techniques, IEEE Transactions on Instrumentation and Measurement, vol. 19 (1970) 377-382.

[19] W. B. Weir, Automatic Measurement of Complex Dielectric Constant and Permeability at Microwave Frequencies, Proceedings of the IEEE, vol. 62, no. 1 (1974) 33-36. 
[20] J. R. Baker-Jarvis, M. D. Janezic, B. F. Riddle, R. T. Johnk, C. L. Holloway, R. G. Geyer, C. A. Grosvenor, NIST Technical Note 1536, Measuring the Permittivity and Permeability of Lossy Materials: Solids, Liquids, Metals, Building Materials, and Negative-Index Materials, February 01, 2005

[21] G. S. Agarwal, Interaction of electromagnetic waves at rough dielectric surfaces, Phys. Rev. B, vol. 15, nº 4 (1977) 2371-2383.

[22] L. F. Chen, C. K. Ong, C. P. Neo, V. V. Varadan,V. K. Varadan, Microwave Electronics: Measurement and Materials Characterization, John Wiley \& Sons (2004).

[23] Air-Gap Effect in Rectangular Waveguide Containing a Lossy H-Plane Dielectric Slab, J. B. Ness and M. W. Gunn, I3EE Transactions on Microwave Theory and Techniques, vol. 26, no. 11 (1978) 894-897.

[24] Agilent, Basics of Measuring the Dielectric Properties of Materials: https://www.google.fr/search?q=Agilent+Basics+of+Measuring+the+Dielectric+Properties+of +Materials\&ie $=$ utf-8\&oe $=$ utf-8\&client=firefox-b\&gfe_rd=cr\&ei=Q-_tWILaE-H$8 \mathrm{AeA} 9 \mathrm{IKoCw}$

[25] M.S. Venkatesh and G.S.V. Raghavan, An overview of dielectric properties measuring techniques, Canadian Biosystems Engineering, vol. 47 (2005) 7.15-7.30.

[26] T. P. Marsland, S. Evans, Dielectric measurements with an open-ended coaxial probe. IEE Proceedings H - Microwaves, Antennas and Propagation, vol. 134, no. 4 (1987) 341-349.

[27] B. Filali, F. Boone, J. Rhazi, G. Ballivy, Design and Calibration of a Large Open-Ended Coaxial Probe for the Measurement of the Dielectric Properties of Concrete, IEEE Transactions on Microwave Theory and Techniques, vol. 56, no. 10 (2008) 2322-2328.

[28] J. E. Atwater, R. Richard, Jr. Wheeler, Complex permittivities and dielectric relaxation of granular activated carbons at microwave frequencies between 0.2 and $26 \mathrm{GHz}$, Carbon, vol. 41 (2003) 1801-1807. 
[29] C. Méjean, L. Pometcu, R. Benzerga, A. Sharaiha, C. Le Paven-Thivet, M. Badard, P. Pouliguen, Electromagnetic absorber composite made of carbon fibers loaded epoxy foam for anechoic chamber application, Materials Science and Engineering B 220 (2017) 59-65.

[30] American National Standards Institute, ANSI C63.5, American National Standard for Calibration of Atennas Used for Radiated Emission Measurements in Electromagnetic Interference (EMI) Control, 16 June 1988. 


\section{List of Figure Captions :}

Fig. 1. (a) Schematic system of measurement and (b) Anechoic chamber of Institute of Electronics and Telecommunications of Rennes situated at INSA Rennes, France.

Fig. 2. X-band waveguide measurement setup.

Fig. 3. (a) Photo of the Keysight dielectric coaxial probe (b) configuration of the measurement performed with the dielectric coaxial probe.

Fig. 4. (a) Reflection coefficient for the material alone, (b) Reflection coefficient for the material backed by a metallic plate, (c) Permittivities and (d) tan $\delta$ extracted from the freespace measurements for different carbon fibers loads.

Fig. 5. (a) Reflection coefficients, (b) tranmission coefficients from waveguide, (c) Permittivity and (d) $\tan \delta$ extracted from the waveguide measurements for different carbon fiber loads.

Fig. 6. Representation of the air holes inside the carbon fiber (CF) loaded composite samples.

Fig. 7. (a) Permittivity and (b) tan $\delta$ obtained using the dielctric coaxial probe measurement for different carbon fibers loaded composites.

Fig. 8. Needed samples for the caracterization techniques in: (a) free space (b) X-band waveguide, (c) coaxial dielectric probe and (d) optical microscope image of the carbon fibers loaded foam structure.

Fig. 9. (a) The pyramid geometry used for simulations and (b) The photo of the achieved loaded epoxy prototype. 
Fig. 10. Simulations and measurement results of the pyramidal absorber prototype made of 0.5 wt.\% carbon fibers loaded epoxy foam. 
Figure. 1

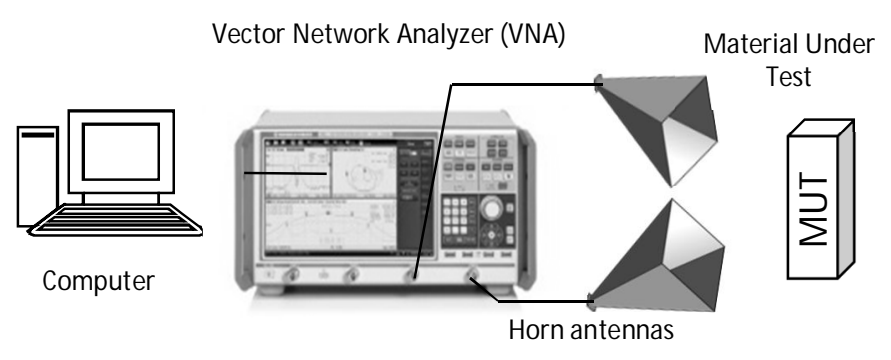

(a)

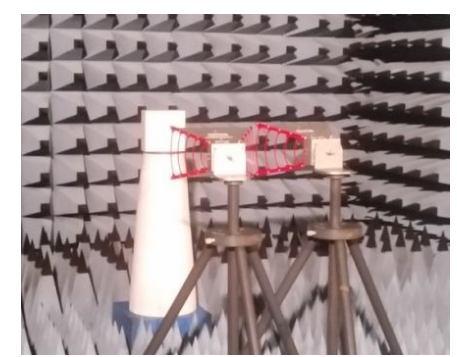

(b)

Fig. 1. (a) Schematic system of measurement and (b) Anechoic chamber of Institute of Electronics and Telecommunications of Rennes situated at INSA Rennes, France 
Figure. 2

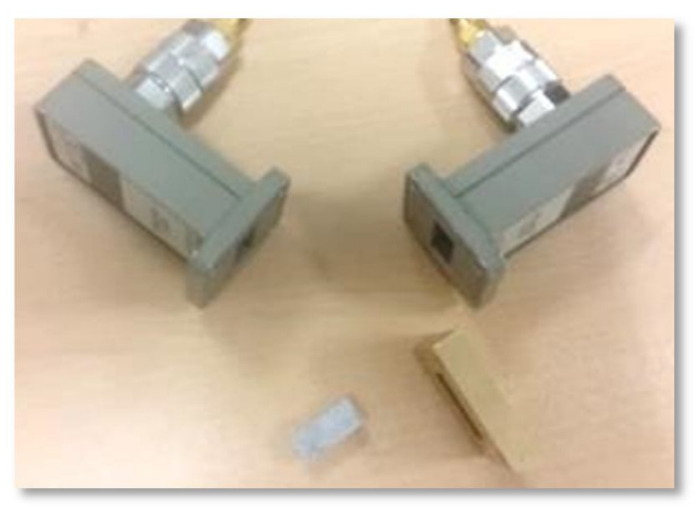

Fig. 2. X-band waveguide measurement setup 
Figure. 3

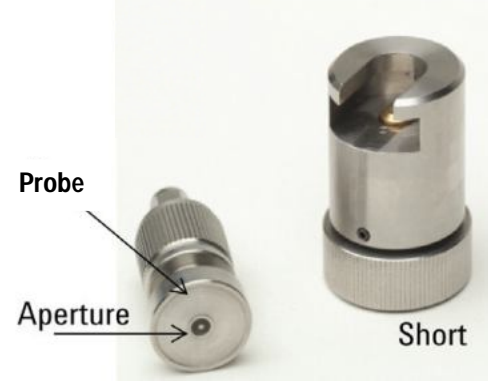

(a)

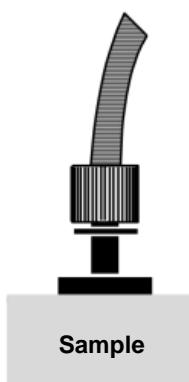

(b)

Fig. 3. (a) Photo of the Keysight dielectric coaxial probe (b) configuration of the measurement performed with the dielectric coaxial probe. 


\section{Figure. 4}

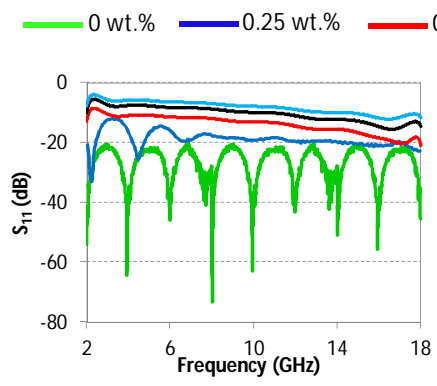

(a)

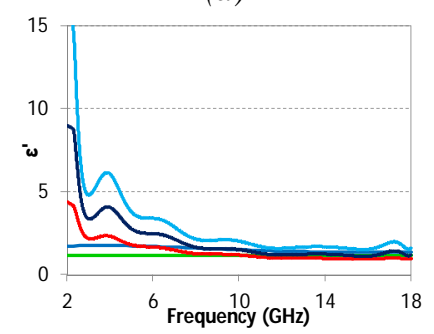

(c)

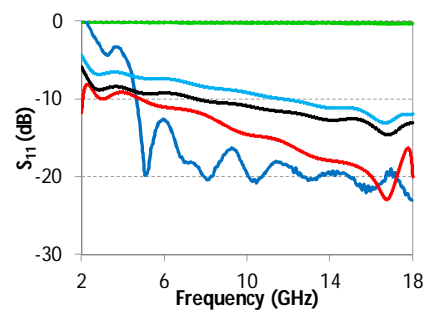

(b)

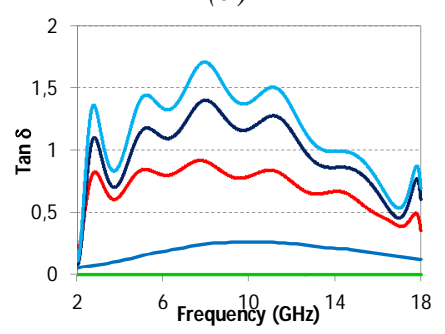

(d)

Fig. 4. (a) Reflection coefficient for the material alone, (b) Reflection coefficient for the material backed by a metallic plate, (c) Permittivity and (d) Tan $\delta$ extracted from the freespace measurements for different carbon fiber loads. 


\section{Figure. 5}

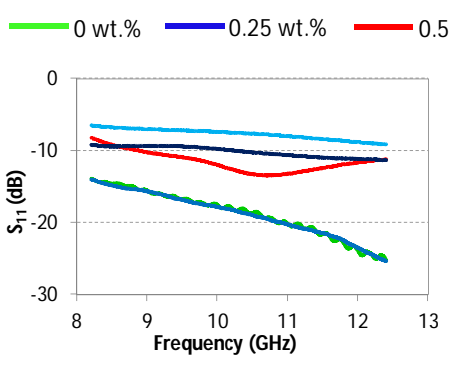

(a)

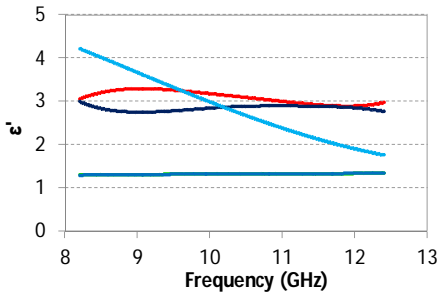

(c)

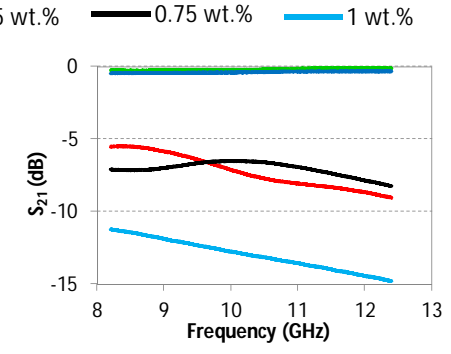

(b)

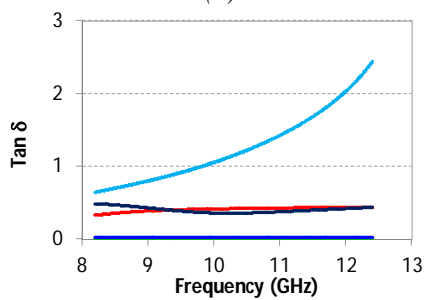

(d)

Fig. 5. (a) Reflection coefficients, (b) tranmission coefficients from waveguide, (c)

Permittivity and (d) Tan $\delta$ extracted from the wave guide measurements for different carbon fiber loads. 
Figure. 6

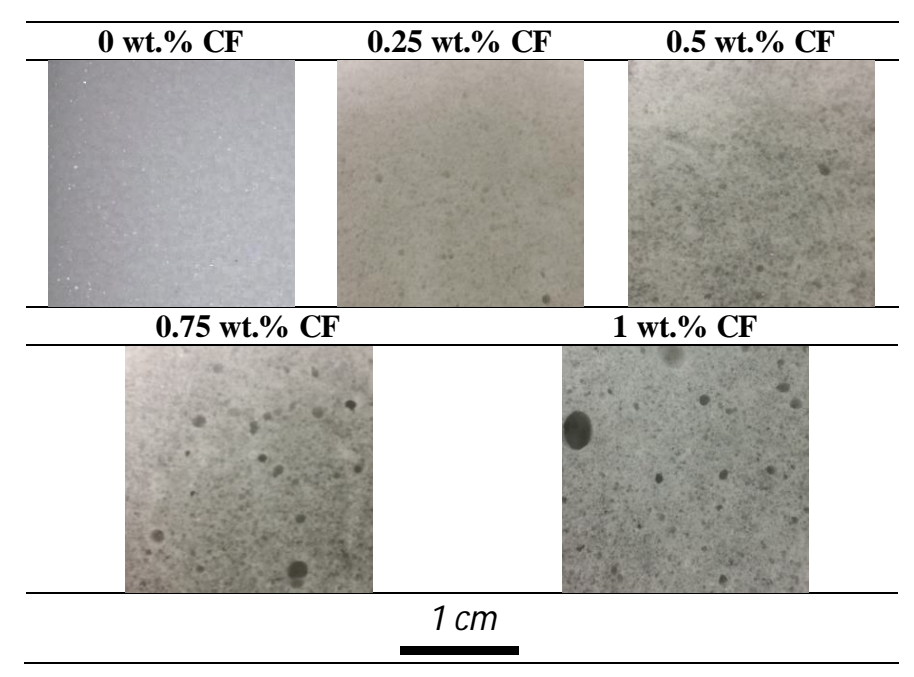

Fig. 6. Representation of the air holes inside the carbon fiber $(\mathrm{CF})$ loaded composite samples. 
Figure. 7

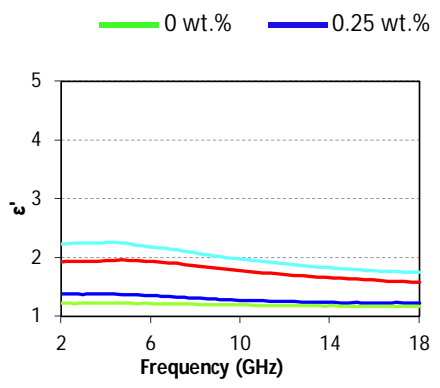

(a)

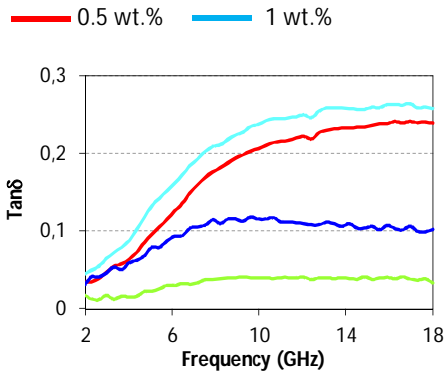

(b)

Fig. 7. (a) Permittivity and (b) Tan $\delta$ obtained using the dielctric coaxial probe measurement for different carbon fibers loaded composites. 
Figure. 8
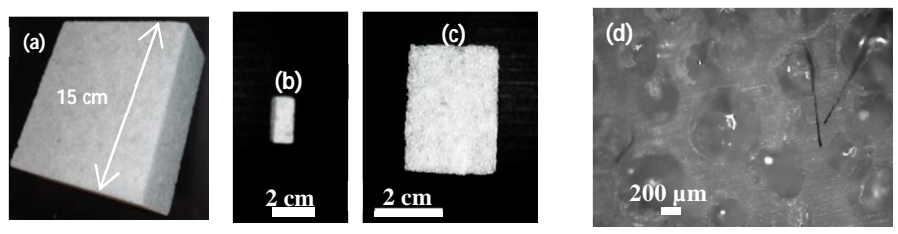

Fig. 8. Needed samples for the caracterization techniques in: (a) free space (b) X-band waveguide, (c) coaxial dielectric probe and (d) optical microscope image of the carbon fibers loaded foam structure. 
Figure. 9

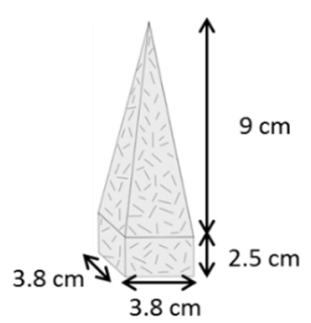

(a)

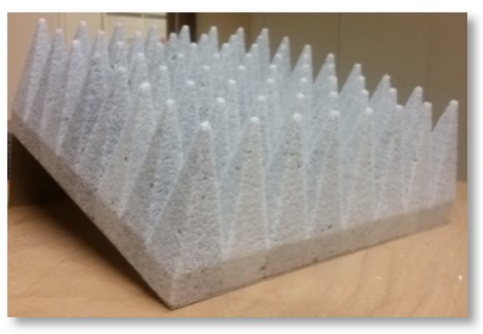

(b)

Fig. 9. (a) The pyramid geometry used for simulations and (b) The photo of the achieved loaded epoxy prototype. 
Figure. 10

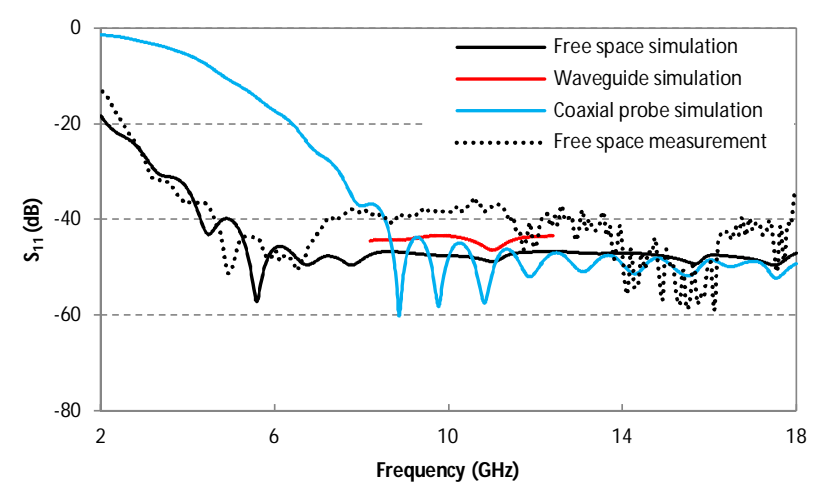

Fig. 10. Simulations and measurement results of the pyramidal absorber prototype made of 0.5 wt. \% carbon fibers loaded epoxy foam. 